\title{
PERSOONIAL Reflections
}

\section{Editorial Note}

Persoonia was established in 1959 as an international journal of mycology named in honour of Christiaan Hendrik Persoon, who is generally regarded as the 'Father of Systematic Mycology'. In recent years Persoonia has focused mainly on fungal systematics of basidiomycetes (Leelavathy et al. 2006, Manimohan et al. 2006, Pradeep \& Vrinda 2006, Robich 2006, Bañares et al. 2007, Bas \& Arnolds 2007, Clémençon 2007, Corriol \& Moreau 2007, Gates \& Noordeloos 2007, Moreno \& Esteve-Raventós 2007, Moreno et al. 2007), with very few papers directed towards other topics and subject areas of mycology.

Because mycology is a dynamic and rapidly changing field of science, the National Herbarium of the Netherlands (NHN), hitherto the sole publisher of Persoonia, decided to establish a strategic alliance with the CBS Fungal Biodiversity Centre (CBS) to jointly publish the journal. Furthermore, it was decided that Persoonia would focus on papers dealing with molecular systematics and evolution of fungi.

Persoonia will henceforth be an international, peer-reviewed, open-access, full colour, fast-track journal, with papers published within 1-2 weeks after acceptance. Published papers are immediately distributed to several libraries (for effective publication under the International Code of Botanical Nomenclature). Papers are bound into two volumes per year (June and December), which can be ordered online.

The journal strongly supports good practice policies, and requires herbarium voucher specimens to be deposited in a herbarium with an online database such as the National Herbarium of the Netherlands (L), and cultures in long-term genetic resource collections such as the Centraalbureau voor Schimmelcultures (CBS), sequences in GenBank/EMBL/DDBJ, alignments in TreeBASE (or other online databases), and taxonomic novelties in MycoBank.

\section{Book Reviews}

Simmons EG. 2007. Alternaria: An Identification Manual. CBS Biodiversity Series No. 6. Pp. 775; 2 colour figures, 288 line drawings, A4 format, hard cover. Price $170 €$. CBS Fungal Biodiversity Centre, ISBN: 978-9070351-68-7.

Alternaria is one of those hyphomycete genera that strikes fear into the heart of those who isolate and identify fungi. Its species occur everywhere,

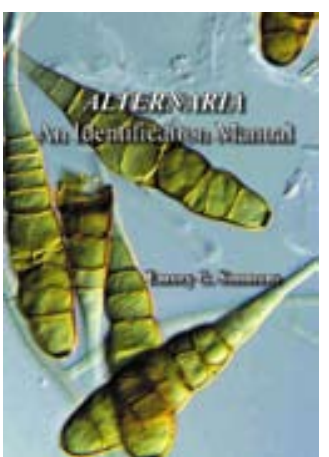

\section{REFERENCES}

Bañares Á, Antonín V, Moreno G. 2007. Gymnopus beltraniae, a new species of section Vestipedes (Agaricales) from the Canary Islands (Spain). Persoonia 19: 255-259.

Bas C, Arnolds EJM. 2007. Hygrocybe comosa, a remarkable new agaric from the French Jura. Persoonia 19: 251-254.

Clémençon H. 2007. Pseudobaeospora calcarea, a new species of agaricoid hymenomycetes. Persoonia 19: 279-287.

Corriol G, Moreau P-A. 2007. Agaricus (Annularía) fenzlii redécouvert dans les Pyrénées. Notes sur le genre Chamaeota en Europe. Persoonia 19: 233-250.

Gates, GM, Noordeloos M. 2007. Preliminary studies in the genus Entyloma in Tasmania - 1. Persoonia 19: 157-226.

Leelavathy KM, Manimohan P, Arnolds EJM. 2006. Hygrocybe in Kerala State, India. Persoonia 19: 101-151.

Manimohan P, Noordeloos ME, Dhanya AM. 2006. Studies on the genus Entoloma (Basidiomycetes, Agaricales) in Kerala State, India. Persoonia 19: 45-93.

Moreno G, Esteve-Raventós F. 2007. A new corticicolous species of the genus Tubulicium (Polyporales) from Southern Spain. Persoonia 19: 227-232.

Moreno G, Esqueda M, Pérez-Silva E, Herrera T, Altés A. 2007. Some interesting gasteroid and secotioid fungi from Sonora, Mexico. Persoonia 19: 263-278.

Pradeep CK, Vrinda KB. 2006. New and noteworthy species of Pluteus (Pluteaceae, Agaricales) from Kerala State, India. Persoonia 19: 95-99.

Robich G. 2006. A revised key to the species of Mycena section Fragilipedes of the Northern Hemisphere. Persoonia 19: 1-43.

\section{Editors-in-Chief:}

Prof. dr PW Crous

CBS Fungal Biodiversity Centre, Uppsalalaan 8, 3584 CT Utrecht, The Netherlands.

Dr ME Noordeloos

National Herbarium of the Netherlands, Leiden University branch, P.O. Box 9514, 2300 RA Leiden, The Netherlands.

as plant pathogens, in indoor air, on spoiling food. In contrast to the similarly intimidating genera Aspergillus, Fusarium and Penicillium, Alternaria has never been monographed. The impressive 1945 thesis by Neergaard included only 16 species, and the influential Dematiaceous Hyphomycetes books by M.B. Ellis considered 44 species in a typically minimalist fashion. Like its predecessors by Raper \& Fennell in Aspergillus, Wollenweber \& Reinking in Fusarium, and Thom \& Raper in Penicillium, this Alternaria manual will be studied diligently in the coming decades and will set the standard for future taxonomic work on this genus. 
Identification of microfungi is not for the faint-hearted, and the existence of an authoritative monograph does not necessarily make the task easy. The author, who in his idiosyncratic style refers to himself as E.G.S. rather than writing in the first person, provides detailed instructions for growing Alternaria species in culture. This standardised culture regime requires two (or three) media, and thoughtful examination of sporulating structures using dissecting and compound microscopes. The major groupings in the key rely on conidium characters and sporulation patterns; for many users, the host index at the end of the book will provide a 'cheat' around the challenging key. The author recommends calibrating cultivation conditions by comparing in-house grown reference cultures with his descriptions.

The bulk of the manual includes detailed descriptions of about 300 species, most grown in axenic culture, including 88 new species or new combinations. The author describes three new genera and resurrects Prathoda Subram., but provides few arguments to justify the segregation. The descriptions are models of micromorphological observation, and must be thoroughly studied before the nuances defining each species can be understood. The discussions are shorter than those in the 'Alternaria, themes and variations' series published in Mycotaxon over the past 27 years, which serve as the source for much of the data in this book. Each species is illustrated with one or two line drawings, lacking stippling to indicate pigmentation; there are only three photographs in the book, intended to aid with the interpretation of the line drawings. I would have appreciated more details of plant pathology, such as the host plant tissues the fungi colonize, and on known geographical distributions. The book concludes with a nomenclator, or 'catalogue raisoné', which brings order to the $>1000$ species attributed to this genus.

Ultimately, the reputation of this book will lie with the author's insistence that the morphological entities he sees and describes are indeed species. This is one of the rare fungal revisions where morphological species concepts are narrower than what is evident from DNA-sequence based phylogenetics. The 'small-spored' $A$. alternata complex, which includes many plant pathogens, is the most critical example. To date, the segregate taxa recognised by the author are not consistently emerging from multigene phylogenies. E.G.S. has little sympathy for the failure of these methods to support his views. His analysis of this topic will amuse some readers and enrage others, and will serve as a reminder of a tumultuous time in fungal taxonomy.

No monograph is ever complete, and even as this book begins its reign as the authoritative voice of Alternaria taxonomy, new species are being described, especially from China. The practitioners of hyphomycetes taxonomy can be grateful for this milestone, but the challenge of identifying Alternaria species will continue. I look forward to facing my own fear, to trolling through the leaves and fruits, knowing that for the first time, I have a chance to put a name on these fungi.

K.A. SEIFERT
Dugan FM. 2008. Fungi in the Ancient World: How Mushrooms, Mildews, Molds, and Yeast Shaped the Early Civilizations of Europe, the Mediterranean, and the Near East. Pp. 152; 13 black and white figures, $15 \times 23$ $\mathrm{cm}$, soft cover. Price 69 USD. APS Press, ISBN 978-0-89054-361-0.

Over the past few years the mycological community has been treated to several entertaining books involving fungi. Although Dugan's title hints at being a similar type of book, it is not.

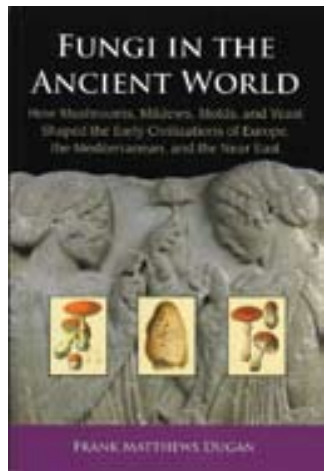
It is a far more factual and history-orientated than other similar products you may find on sites such as Amazon.com. The author has made a good attempt to deliver what his title promises. The book portrays various times in human history where fungi have played a significant role, and even influenced the course of history. This book may provide interesting antidotes for teachers and lecturers looking to spice up their lessons. The book consists of 15 chapters, as well as a concluding chapter. Each chapter has a specific layout, namely an extended abstract about the topic covered in the chapter, followed by a more detailed examination of the literature, in an attempt to support or refute some commonly accepted statements or facts about fungi and history. The way it is written makes a clear separation between the generalist (who will read the abstract), and the historian (who will delve into the supporting text). Given this specific structure chosen by the author, the text reads less fluidly than it could had some of the cross references in support of the various statements been omitted.

Several interesting aspects come to the reader's attention. For instance, Egyptian brewing practices emphasised the use of beer bread as a starter culture. Interestingly the Egyptian hieroglyphic for beer resembles a budding yeast (lost knowledge!), and it is also postulated that beer production may have been the primary impetus for the domestication of cereals. The hypothesis that the oldest domesticated plant may be yeast, is now definitely sunk, as fungi are now known to be more closely related to animals than plants. That the original purpose of wine barrels was to facilitate storage for transport and trade, and not to add to the bouquet, was a fact I found intriguing. Similarly, that the word 'symposium' in effect means drinking party, is probably a less startling revelation to many of us. Its is quite shocking to read that Linnaeus, who was widely celebrated last year, largely ignored the use and context of ancient names when it came to erecting new fungal genera. Furthermore, in 2007 the European Union again saw an increase in the number of asylum seekers for the first time in many a year. It's therefore interesting to read that a resident alien of Athens was once awarded citizenship in exchange for a dish of truffles! This is probably a story the Greeks would have preferred kept secret! In Chapter 4, Dugan explores 'Fungi as Entheogens'. His statement that most religions have their roots in experiences with the ingestion of psychoactive fungi is probably not surprising to many of us. However, on p. 27 Amanita muscaria gets linked to all religions in the Middle East, which is a revelation that will probably not get into any textbook used in the region. The question 
if Stachybotrys atra really could have been responsible for the tenth plague of Egypt (death of the first born), is discussed in Chapter 5, while lichens as fabric dyes are briefly mentioned in Chapter 6. Chapter 7 deals with plant pathogenic fungi, but focuses for a large part on seed-born fungi, while Chapter 8 , fungi as agents of rot, is rather skimpy, and could best have been left untreated. I also found chapters on human and animal pathogens, the ecological role of fungi, and fungi in glacial ice to be rather brief. Chapter 14, 'Ideas of the ancients on fungal biology', is dealt with in two and a half pages, leaving the reader to conclude that the ancients couldn't have had many ideas on the subject.
Looking at the book as a mycological text, I am sure that it took many hours of careful research to assemble all the various facts presented here. However, as mentioned before, some chapters are a little on the thin side (due perhaps to paucity of information being available to the author), and would probably have been better left excluded. What is also a bit disappointing is the lack of figures to illustrate the text. It would have been more appealing to both readers and teachers if the text was better illustrated. Nevertheless, this book will make a welcome contribution to the bookshelf of many an interested mycologist, as it discusses some very controversial issues.

P.W. CRous

\section{Correcting the Impact Factors of Taxonomic Journals by Appropriate Citation of Taxonomy (ACT)}

The ISI Web of Science impact factor ranks journals by their frequency of citation, and the related $\mathrm{H}$-factor similarly ranks an author's published work. These statistics are increasingly used by senior managers to evaluate individual scientists and sometimes whole departments or institutions. Some argue that the criteria used to calculate these values make it very difficult for taxonomists and taxonomic journals to perform well (Krell 2000, 2002, Garfield 2001, Agnarsson \& Kuntner 2007). This may be true, but it is also true that the solution may not rest completely with ISI.

Taxonomists can positively influence their fate in this system by being proactive and more fastidious in their literature citations. Traditionally, taxonomists gained credit for their discoveries and conclusions by having their names appended to taxonomic binomials. The taxon-author combination was used in subsequent works. This practise is no longer enforced in many scientific journals, including some taxonomic ones. By modern standards, it is an ineffective means of accrediting taxonomic work. If taxonomists want to benefit from the contemporary system of citation analysis, they must adapt to the simple rules that it follows.

We propose that all taxonomists and taxonomic journals in all disciplines adopt a code of practise that we call Appropriate Citation of Taxonomy (or ACT). The principal is to ensure that common elements of taxonomic papers, generally considered de facto citations by taxonomists but not by ISI, are presented in a format that is considered a valid citation by ISI. For example, the use of a Latin binomial and the associated species concept is an implied citation of a taxonomic concept: authors employing such information should formally cite the taxonomic papers where they originate. Taxonomists now routinely use GenBank accession numbers in their studies; authors should make a concerted effort to track down and cite the studies where these DNA sequences were generated. Research that relies on specimens of living cultures should cite the original research that resulted in the collection or isolation of these specimens or cultures. In studies employing many names, sequences, or specimens, it may not always be possible to cite every paper without extending the reference list beyond the length tolerated by editors. In such cases, we suggest an arbitrary value of five names, sequences or specimens be used as a guidepost to determine which papers are most appropriately cited. Taxonomic concepts, DNA sequences, cultures and specimens represent data and intellectual property and should be cited as such. Taxonomic journals suffer the most from the status quo, and should be the first to adopt these principals. Taxonomists who publish in these journals will be beneficiaries as their own work receives more appropriate citation and the journals they favour see their impact factors start to climb. All this can happen without lobbying ISI to change their rules, and there is nothing questionable about the ethics of recommending that taxonomic work receive the citation it actually deserves.

We call upon all taxonomists and taxonomic journals: ACT.

\section{REFERENCES}

Agnarsson I, Kuntner M. 2007. Taxonomy in a changing world: seeking solutions for a science in crisis. Systematic Biology 56: 531-539.

Garfield E. 2001. Taxonomy is small, but it has its citation classics. Nature 413: 107.

Krell FT. 2000. Impact factors aren't relevant to taxonomy. Nature 405: 507-508.

Krell FT. 2002. Why impact factors don't work for taxonomy. Nature 415 957.

K.A. Seifert

Biodiversity (Mycology \& Botany), Agriculture and Agri-Food Canada, Ottawa, Ontario K1A 0C6 Canada.

P.W. Crous

CBS Fungal Biodiversity Centre, Uppsalalaan 8, 3584 CT Utrecht, The Netherlands.

J.C. Frisvad

BioCentrum-DTU, Technical University of Denmark, DK-2800 Kgs. Lyngby, Denmark. 


\section{The All-Fungi DNA Barcoding Campaign (FunBOL)}

DNA barcoding is the use of a standardised DNA sequence to identify species from all kingdoms of life. The initiative to develop a well-funded international project (iBOL, www. dnabarcoding.org) is gaining momentum. Fourteen mycologists, who now comprise FunBOL (www.allfungi.org), met in Toronto, Canada on 30 April 2008 to discuss strategies to enhance the profile of fungi in what is becoming a significant international scientific movement. It is now clear that the ITS (internal transcribed spacer of the nuclear ribosomal DNA) will be formally proposed as the fungal barcode to the Consortium for the Barcode of Life (CBOL, www.barcoding.si.edu). The animal barcode gene, cytochrome oxidase 1 (Cox1 or CO1), is problematic for fungi because of the need for multiple primers and the unpredictable occurrence of long introns. The accumulated volume of fungal ITS sequences and the comfort of mycologists with using this region to identify species make it the most sensible candidate barcode.

A strong interest in DNA barcoding was expressed by several mycologists at various international meetings held in 2007. CBOL offered its assistance to FunBOL in developing networks of fungal barcoders working on common projects, and to facilitate obtaining funding for these projects. Mycologists who want to pursue DNA barcoding projects should contact members of FunBOL, or representatives of $\mathrm{BBOL}$ in their own countries.

But first, the ITS must be designated the official barcode. To qualify for the BARCODE keyword in GenBank, EMBL or DDBJ, sequences must represent an approved barcode region, be explicitly linked with a voucher specimen or culture, and the chromatogram must be deposited with the sequence accession. At the Toronto meeting, a plan was established to quickly fulfil the formalities to designate the ITS as the fungal barcode.

We urge mycologists to include the ITS locus in their DNA sequencing studies, and to pay close attention to the need for vouchers and sequence chromatograms. ITS chromatograms can presently be deposited in EMBL, MycoBank and BOLD, and this feature will become available in GenBank, once CBOL officially approves the ITS as barcode domain for fungi. It is critical that the fungal barcode library grow rapidly once official status is granted. This will also enable the fungal community to lobby more successfully for DNA Barcode funding, and to assume a more prominent position within $\mathrm{BO}$.

Persoonia will pay special attention to DNA barcoding issues relevant to mycologists. Furthermore, a special issue of Studies in Mycology is being planned as part of the Darwin celebrations in 2009.

\section{K.A. Seifert}

Biodiversity (Mycology \& Botany), Agriculture and Agri-Food Canada, Ottawa, Ontario K1A 0C6 Canada.

P.W. Crous

CBS Fungal Biodiversity Centre, Uppsalalaan 8, 3584 CT Utrecht, The Netherlands.

\section{Calibrating Europe's Biodiversity using DNA barcodes}

The life sciences suffer from the lack of a unified species reference system with established species names. Modern sequencing methods produce enormous amounts of environmental data, which can only be interpreted efficiently if sufficient reference points are known. For example, the environmental response in biota to climatic change or human activities cannot be monitored efficiently without such a reference. Under current conditions, even documenting the status quo and comparing observations across Europe is an unnecessarily laborious task. These problems are being address in pan-European efforts like EDIT ('unifying taxonomy') or LifeWatch. However, these efforts could be massively facilitated by establishing a European species reference system, where DNA barcoding activities can be up-scaled and centralised via a Network of European Leading Laboratories (NELL). This approach would lead to the production of huge amounts of reference data, while at the same time providing a basis for molecular-based biodiversity monitoring in areas relevant for conversation.

Europe has the collections, the expertise, and the expert workforce needed to make a significant contribution to the international barcode initiative. European barcoding activities are currently coordinated under WP3 of EDIT (www.ecbol. org). In contrast to the US or Canada, Europe lacks the capital investment in physical research infrastructure and support for DNA barcoding on a large scale. Thanks to DNA sequencing technology and the proven protocols for DNA barcoding, 'horizontal genomics' projects such as those proposed to the EuroBioFund www.esf.org/eurobiofund/strasbourg) can best operate on an industrial, mass-production scale, just as the Human Genome Project did. The present proposal has several work packages of interest to mycologists, ranging from barcoding European Type Specimens, Indoor Air \& Food, Plant Health \& Quarantine, Human Health, Environmental Monitoring, Nature Conservation, to Biodiversity and Natural Products. Scientists from several EU countries are already participating in the draft proposal. Mycologists who want to become involved should contract ECBOL via barcode@cbs.knaw.nl.

P.W. Crous

CBS Fungal Biodiversity Centre, Uppsalalaan 8, 3584 CT Utrecht, The Netherlands. 


\section{Symposium Announcement: Fungi and Health}

Date: 13 and 14 November 2008

Venue: Trippenhuis, KNAW Amsterdam.

Registration is free. Lunch $€ 12.50$ per day (details will follow)

This year it will be two hundred years since King Louis Napoleon (brother of Napoleon Bonaparte) founded the Royal Institute of Science, Letters and Fine Arts, the forerunner of the Royal Netherlands Academy of Arts and Sciences. The Academy is celebrating this landmark year (KNAW 200) by organising a wide variety of different events. One of these events is that the various Academy institutes will present their research in a series of special symposia. The CBS Fungal Biodiversity Centre has chosen November 13 and 14 with the symposium 'Fungi and Health' The symposium will consist of six sessions, each with a special topic.

\section{Preliminary programme:}

\section{Session 1. FUNGI AND OUR HEALTH}

Speakers: David Denning (Manchester), Paul Verweij (Nijmegen), Sybren de Hoog (CBS Utrecht), Jacques Guillot (Maisons-Alfort).

\section{Session 2. FOOD SAFETY}

Speakers: GianCarlo Perrone (Bari), Naresh Magan (Bedford), Noel Van Peij (Delft), Johan Schnurer (Uppsala)

Session 3. LIVING IN HEALTHY ENVIRONMENTS

Speakers: Brian Flannigan (Edinburgh), Thomas Warscheid (Bremen), Olaf Adan (Eindhoven/Delft), Robert A Samson (CBS Utrecht).

Session 4. CULTURE COLLECTION, DNA BARCODING AND BIOSECURITY

Speakers: Erko Stackebrandt (Braunschweig), G. Cardinali (Perugia), F. Dromer (Paris) J. Stalpers (CBS Utrecht), U. Eberhardt (CBS Utrecht)

Session 5. YEASTS AND HEALTH

Speakers: Robin May (Birmingham) Arturo Casadevall (New York) Tom Dawson (Cincinnati). Piet de Groot (Amsterdam). Session 6. FUNGI AND HEALTHY PLANTS

Speakers: Zakkie Pretorius (South Africa), Peter Bonants (Wageningen), Ariena van Bruggen (Wageningen), Bruce Fitt (Rothamsted).

For detailed information, consult www.cbs.knaw.nl.

\section{Taxonomic novelties in this issue}

Species

Batcheloromyces sedgefieldii Crous, sp. nov. (p. 65)

Calosphaeria africana Damm \& Crous, sp. nov. (p. 43)

Catenulostroma wingfieldii Crous, sp. nov. (p. 67)

Cheirosporium L. Cai \& K.D. Hyde, gen. nov. (p. 55)

Cheirosporium triseriale L. Cai \& K.D. Hyde, sp. nov. (p. 55)

Dissoconium musae Arzanlou \& Crous, sp. nov. (p. 24)

Dissoconium proteae Crous, sp. nov. (p. 68)

Jattaea mookgoponga Damm \& Crous, sp. nov. (p. 47)

Jattaea prunicola Damm \& Crous, sp. nov. (p. 45)

Mycosphaerella mozambica Arzanlou \& Crous, sp. nov. (p. 26)

Paraconiothyrium africanum Damm, Verkley \& Crous, sp. nov. (p. 14)

Paraconiothyrium hawaiiense (Crous) Damm, Crous \& Verkley, comb. nov. (p. 16)

Paraconiothyrium variabile Riccioni, Damm, Verkley \& Crous, sp. nov. (p. 13)

Phaeoacremonium fuscum L. Mostert, Damm \& Crous, sp. nov. (p. 93)

Phaeoacremonium pallidum Damm, L. Mostert \& Crous, sp. nov. (p. 93)

Phaeoacremonium prunicolum L. Mostert, Damm \& Crous, sp. nov. (p. 94)

Phaeothecoidea proteae Crous, sp. nov. (p. 71)

Pseudocercospora assamensis Arzanlou \& Crous, sp. nov. (p. 28)

Pseudocercospora indonesiana Arzanlou \& Crous, sp. nov. (p. 29)

Pseudocercospora longispora Arzanlou \& Crous, sp. nov. (p. 30 )

Stenella musae Arzanlou \& Crous, sp. nov. (p. 31)

Stenella musicola Arzanlou \& Crous, sp. nov. (p. 33)

Stenella queenslandica Arzanlou \& Crous, sp. nov. (p. 34)

Teratosphaeria knoxdavesii Crous, sp. nov. (p. 75)

Teratosphaeria marasasii Crous, sp. nov. (p. 79)

Teratosphaeria persoonii Crous \& L. Mostert, sp. nov. (p. 80)

Togninia africana Damm, L. Mostert \& Crous, sp. nov. (p. 95)

Togninia griseo-olivacea Damm, L. Mostert \& Crous, sp. nov. (p. 97)
Gene loci sequenced

ITS

ITS, TUB, SSU, LSU

ITS

ITS, LSU

ITS, LSU

ITS, ACT, HIS, SSU

ITS

ITS, TUB, SSU, LSU

ITS, TUB, SSU, LSU

ITS, ACT, HIS, SSU

ITS, SSU

ITS, SSU

ITS, SSU

ITS, TUB, ACT, SSU

ITS, TUB, ACT, SSU

ITS, TUB, ACT, SSU

ITS

ITS, ACT, HIS, SSU

ITS, ACT, HIS, SSU

ITS, ACT, HIS, SSU

ITS, ACT, HIS, SSU

ITS

ITS

ITS

ITS

ITS

ITS, TUB, ACT, SSU

ITS, TUB, ACT, SSU 